\title{
Prosody and temporal productions in Greek
}

Antonis Botinis ${ }^{1}$, Athina Kontostavlaki ${ }^{1}$, Evgenia Magoula ${ }^{2}$, Olga Nikolaenkova $^{3}$, Charalambos Themistocleous ${ }^{4}$

${ }^{1}$ Lab of Phonetics \& Computational Linguistics, University of Athens, Greece

${ }^{2}$ Department of Primary Education, University of Athens, Greece

${ }^{3}$ Department of General Linguistics, Saint Petersburg State University, Russia

${ }^{4}$ Department of Swedish, University of Gothenburg, Sweden

https://doi.org/10.36505/ExLing-2018/09/0005/000338

\begin{abstract}
In this study, we have investigated the temporal patterns of syllable onsets, nuclei, and codas in Greek. The main findings showed significant effects of stress and focus on syllable constituents, which suggest complex effects of lexical and sentence prosody on intrasyllabic constituents. Nevertheless, there was no significant effect of syllable constituents and focus on the overall syllable duration despite the fact that consonants at coda position differed in their intrinsic duration. This finding suggests that the syllable exercises control over the duration of intersyllable constituents.

Key words: syllable structure, onset, nucleus, coda, focus, stress, Greek
\end{abstract}

\section{Introduction}

Syllable duration depends on a variety of factors such as its internal structure and position, whether it is stressed or focused (Botinis 1989) and whether it carries edge-tones (Themistocleous 2014); Therefore, the duration of segments that make up the syllable is conditioned by its structure and role as a prosodic constituent. This is also evidenced by controlled experiments and studies on free speech (e.g., Greenberg, Carvey, Hitchcock, Chang, 2003). In this study, we look at the temporal patterns of syllable onsets, nuclei, and codas in Greek, in order to uncover prosodic effects on segmental durations.

\section{Experimental methodology}

Four male and five female Athenian speakers produced a set of twelve test words (Table 1) in the carrier phrase ['eleye Oeti'ka] (he was saying positively) either in a fairly neutral way or in focus (see Botinis 1989 relevant discussion). We conducted two regression analyses: in the first, the response variable was the duration of syllable constituents and in the second, the response variable was the total syllable duration. The syllable consituent (onset, nucleus, and coda $\mathrm{Cm}$, $\mathrm{Cn}, \mathrm{C}$ ) ), stress (stressed vs. unstressed), focus (information focus vs. neutral), and their interactions were the predictors in both tests. Statistics were conducted in $\mathrm{R}$ ( $\mathrm{R}$ Core Team, 2016).

ExLing 2018: Proceedings of $9^{\text {th }}$ Tutorial and Research Workshop on Experimental Linguistics, 28-30 August, Paris, Frannce 
26 A. Botinis et al.

Table 1. Test words with antepenultimate and penultimate lexical stress.

\begin{tabular}{lll}
\hline Antepenultimate stress & Penultimate stress & Gloss \\
\hline ['sim.fonos], singular & [sim.' 'fonus], plural & Concession \\
['sim.vulos], singular & [sim.' 'vulus], plural & Advisor \\
['sin.Oetos], singular & [sin.' 'Oetus], plural & Complex \\
['sin.ðezmos], singular & [sin.' 'ezmus], plural & Link \\
['sij.xronos], singular & [sij.' 'xronus], plural & Synchronic \\
['sij.Vrapse], past & [sij.' 'Yrapsi], future & wrote/will write \\
\hline
\end{tabular}

\section{Results}

The results are presented in Figures 1-2 and Tables 2-3. Lexical stress and sentence focus have a lengthening effect on overall syllable duration: unstressed non-focused syllables are $126 \mathrm{~ms}$, stressed and unfocused syllables are $160 \mathrm{~ms}$ and stressed and focused syllables are $163 \mathrm{~ms}$. Also, there are statistically significant effects of stress and focus on duration. Stress has significant effects on syllable nuclei and coda that differ from the intercept (i.e., syllable onsets) in their durations. Also, codas and nuclei differ from onsets and there are significant interactions of foci and stresses on nuclei and codas.

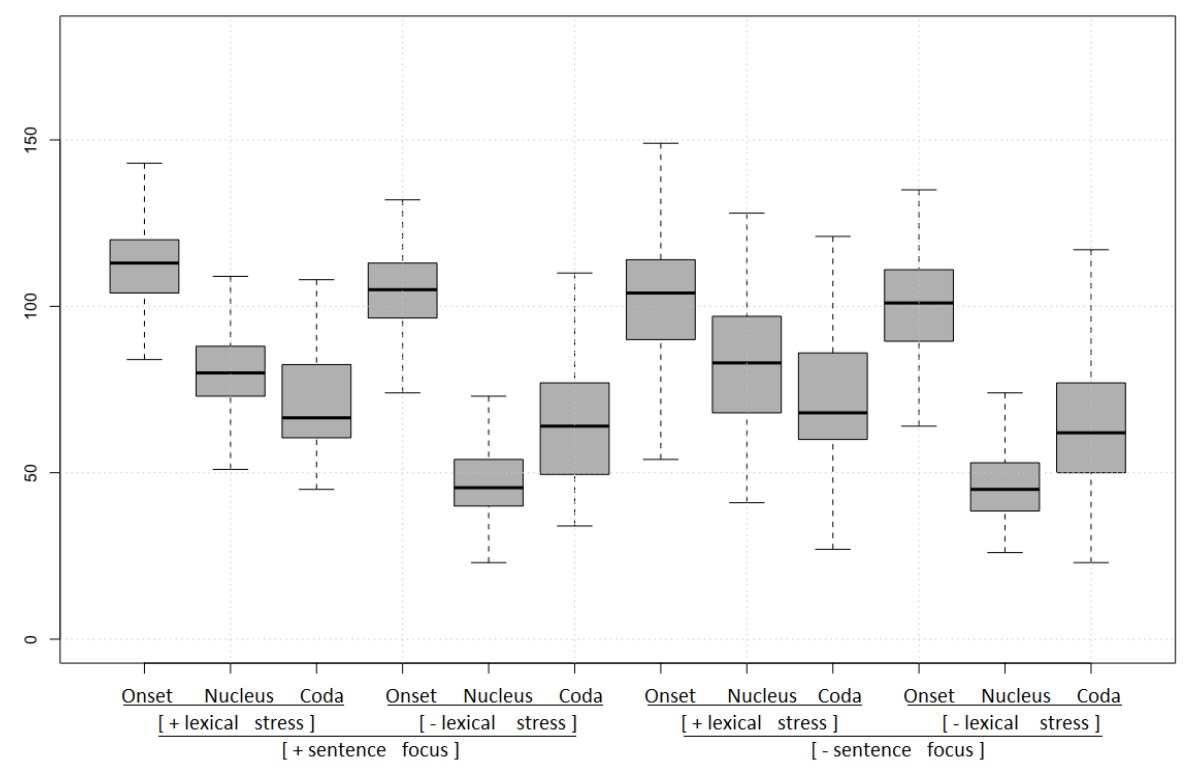

Figure 1. Onset, nucleus and coda syllable constituents as a function of lexical stress and sentence focus. 


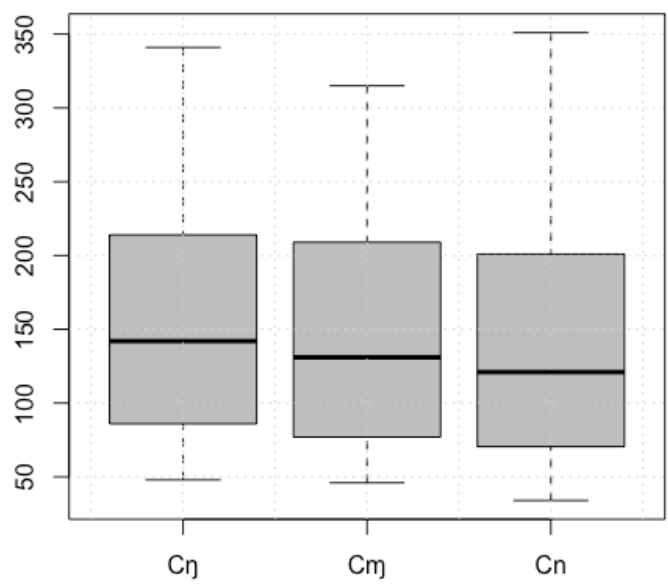

Figure 2 Total syllable duration in $\mathrm{ms}$. for syllables ending with $/ \mathrm{m}, \mathrm{n}, \mathrm{y} /$.

Table 2. Linear regression model for syllable constituent, stress, and focus on duration. The model had a residual standard error: 16.51 on 2277 degrees of freedom; multiple R-squared: 0.5996; Adjusted Rsquared: $0.59 ; \mathrm{F}(11)=310, \mathrm{df}=2277, \mathrm{p}<0.001$.

\begin{tabular}{lllll}
\hline \hline Intercept) & 108.995 & 1.153 & 94.53 & 0.001 \\
\hline Nucleus & -29.576 & 1.631 & -18.13 & 0.001 \\
\hline Coda & -36.79 & 1.631 & -22.56 & 0.001 \\
\hline Unstressed & -5.637 & 1.696 & -3.32 & 0.001 \\
\hline FocusN & -7.589 & 1.627 & -4.66 & 0.001 \\
\hline Nucleus:Unstressed & -26.004 & 2.399 & -10.83 & 0.001 \\
\hline Coda:Unstressed & -1.488 & 2.399 & -0.62 & 0.535 \\
\hline Nucleus:FocusN & 11.015 & 2.3 & 4.78 & 0.001 \\
\hline Coda:FocusN & 7.95 & 2.3 & 3.45 & 0.001 \\
\hline Unstressed:FocusN & 3.923 & 2.398 & 1.63 & 0.102 \\
\hline Nucleus:Unstressed:FocusN & -9.259 & 3.392 & -2.73 & 0.006 \\
\hline Coda:Unstressed:FocusN & -6.008 & 3.392 & -1.77 & 0.076 \\
\hline \hline
\end{tabular}

Nevertheless, a linear regression model with total duration as the dependent variable shows no significant effects of focus and syllable constituent. We observe that stress and syllable constituent (as it is evident by the significnat effect of the coda consonant [n] over the intercept) affect syllable duration $(p<.05)$ significantly. 
Table 3. Linear regression model for syllable constituent, stress, and focus on total syllable duration. The model had a residual standard error: 14.61 on 751 degrees of freedom; multiple R-squared: 0.1813, Adjusted R-squared: $0.17 ; \mathrm{F}(11)=15.12, d f=751, p<0.001$.

\begin{tabular}{lllll}
\hline \hline (Intercept) & 77.25 & 1.92 & 40.27 & 0.001 \\
\hline Cn & 11.47 & 2.71 & 4.23 & 0.001 \\
Unstressed & 5.59 & 2.69 & 2.08 & 0.05 \\
\hline
\end{tabular}

\section{Discussion}

The syllable is one of the fundamental units of speech production across different dimensions including representation, processing and implementation. In this study, we have provided acoustic evidence from Greek syllables that realize the first morpheme of multimorphemic words. The results show that onsets are clearly longer than nuclei and codas. One of the main reasons for that is that the intrinsic duration of sibilant consonants in Greek is long (Themistocleous 2017), which to a certain degree explains this effect. Overall, the syllables do not significantly differ in their total duration despite the fact that their coda consonants differ in their intrinsic duration. One account for this phenomenon is that syllables 'regulate' the duration of their constituents so that there is a tendency to lengthen or shorten their segments to accommodate for their intrinsic duration (about the role of syllables vs. segments, see Hickott 2014). So, this study provides evidence that favors a predominance of syllable over subsyllabic constituents and explains why despite different consonantal realizations of syllables retain their overall duration.

\section{References}

Botinis, A. 1989. Stress and prosodic structure in Greek. Lund University Press.

Greenberg, S., Carvey, H., Hitchcock, L., Chang, S. 2003. Temporal properties of spontaneous speech - a syllable-centric perspective. Journal of Phonetics 31(3-4), 465-485.

Gregory, H. 2014. The architecture of speech production and the role of the phoneme in speech processing. Language, Cognition and Neuroscience 29:1, 2-20.

Hickok, G. 2014. The architecture of speech production and the role of the phoneme in speech processing. Language, Cognition and Neuroscience, 29(1), 2-20.

Themistocleous, Ch. 2014. Edge-tone effects and prosodic domain effects on final lengthening. Linguistic Variation 14(1), 129-160.

Themistocleous, Ch. 2017. Effects of Two Linguistically Proximal Varieties on the Spectral and Coarticulatory Properties of Fricatives: Evidence from Athenian Greek and Cypriot Greek. Frontiers in Psychology 8, 1945. 